\title{
Risk factors for Covid-19 severity and fatality: a structured literature review
}

\author{
Dominik Wolff $^{1}\left[\right.$ D $\cdot$ Sarah Nee ${ }^{1} \cdot$ Natalie Sandy Hickey $^{1} \cdot$ Michael Marschollek $^{1}$
}

Received: 19 June 2020 / Accepted: 17 August 2020 / Published online: 28 August 2020

(c) The Author(s) 2020

\begin{abstract}
Purpose Covid-19 is a global threat that pushes health care to its limits. Since there is neither a vaccine nor a drug for Covid19 , people with an increased risk for severe and fatal courses of disease particularly need protection. Furthermore, factors increasing these risks are of interest in the search of potential treatments. A systematic literature review on the risk factors of severe and fatal Covid-19 courses is presented.

Methods The review is carried out on PubMed and a publicly available preprint dataset. For analysis, risk factors are categorized and information regarding the study such as study size and location are extracted. The results are compared to risk factors listed by four public authorities from different countries.

Results The 28 records included, eleven of which are preprints, indicate that conditions and comorbidities connected to a poor state of health such as high age, obesity, diabetes and hypertension are risk factors for severe and fatal disease courses. Furthermore, severe and fatal courses are associated with organ damages mainly affecting the heart, liver and kidneys. Coagulation dysfunctions could play a critical role in the organ damaging. Time to hospital admission, tuberculosis, inflammation disorders and coagulation dysfunctions are identified as risk factors found in the review but not mentioned by the public authorities.

Conclusion Factors associated with increased risk of severe or fatal disease courses were identified, which include conditions connected with a poor state of health as well as organ damages and coagulation dysfunctions. The results may facilitate upcoming Covid-19 research.
\end{abstract}

Keywords Covid-19 $\cdot$ SARS-CoV-2 $\cdot$ Review $\cdot$ Risk factors $\cdot$ Population at risk

\section{Introduction}

In the end of 2019, a novel respiratory disease, the coronavirus disease 2019 (Covid-19), occurred. The pathogen causing the disease was identified by next-generation sequencing as a novel coronavirus closely related to the SARS-coronavirus discovered in 2003 [1]. According to the WHO guidelines [2], this novel coronavirus was named severe acute respiratory syndrome coronavirus 2 (SARS-CoV-2). First cases of Covid-19 were reported from the Chinese city Wuhan located in the province Hubei in December 2019 [3]. The disease is spreading worldwide and was classified

Dominik Wolff

Dominik.Wolff@plri.de

1 Peter L. Reichertz Institute for Medical Informatics of TU Braunschweig and Hannover Medical School, Hannover, Germany as a pandemic by the WHO in March 2020 [4]. The virus is transmissible from human to human [5] and the number of infected people increases at an exponential rate, exceeding 1 mio. cases on 02.04.2020 and 1.5 mio. cases in 184 countries only a week later $[6,7]$. At various disease hotspots such as New York, the health care system reaches its limits.

For diagnosis, the virus is mainly detected by real-time quantitative polymerase chain reaction (rt-PCR) in throat swabs [8,9]. Due to limited test capacities, which require a special equipped laboratory, patients showing symptoms are tested only. On the onset of Covid-19 typical symptoms are fever, cough, myalgia and fatigue, while headache, sputum production, hemoptysis and diarrhea are less common. In the course of disease a subset of patients show pneumonia with abnormal findings on chest CT [10]. Severe cases are transferred to an intensive care unit (ICU) and frequently require artificial ventilation. The disease's case fatality rate is estimated between $3.4 \%$ and $11 \%$ [11]. 
Although, it depends to a large extent on the number of tests carried out as well as the quality and occupancy rate of local health care.

Until a vaccine is available, an increase in the number of infections must be expected and if not being controlled Covid-19 will exceed the limits of health care systems. Since some groups appear to be at higher risk of serious disease progression and increased mortality, they should be given special protection against an infection. This is particularly important in the context of the much-discussed relaxation of restrictions, such as the prohibition of contact. To identify these vulnerable groups, the risk factors for severe and fatal disease progression must be found. Additionally, the identification of risk factors can contribute to research into the pathophysiological processes of Covid-19 from which possible treatment strategies can be developed. However, information on this is scattered and based on rather small studies. For connecting these, this publication describes a structured literature review on the risk factors of Covid-19 for severe and fatal disease courses. Additionally, the review's results are compared to the risk factors mentioned by four public authorities.

\section{Methods}

Publications of interest describe clinical studies on Covid19 identifying factors for increased risks of severe or fatal disease courses. The review focusses on studies whose patients were diagnosed positive by rt-PCR. The diagnosis by rt-PCR shows a low false-positive rate, but is criticized for a quite high false-negative rate $[12,13]$. The inclusion of rt-PCR diagnoses only reduces the number of false diagnoses to a minimum. Since the disease is new and has only been present since December 2019, the search is carried out on PubMed as well as on the Covid-19 Open Research Dataset (CORD-19) [14] containing mostly yet unpublished publications, so called preprints.

To identify publications of interest, MESH Terms and synonyms for Covid-19 and risk factors are combined leading to the following search term:

("risk factor" OR "determinant" OR "disposition" OR "increased risk" OR "population at risk" OR "health risk behavior") AND ("covid-19" OR "sars-cov-2" OR "covid19" OR "2019-nCov" OR "severe acute respiratory syndrome coronavirus 2 " OR "covid 19").

Furthermore, the search is limited to the English language. It was performed on PubMed on 25.03.2020 and was updated on 17.04.2020. Search results were documented as file export including search term and date.

\section{CORD-19}

The Covid-19 Open Research Dataset (CORD-19) was created by the Allen Institute for AI in partnership with the Chan Zuckerberg Initiative, Georgetown University's Center for Security and Emerging Technology, Microsoft Research, and the National Library of Medicine-National Institutes of Health, in coordination with the White House Office of Science and Technology Policy. It is freely available and updated weekly. The data provided is intended to facilitate the application of natural language processing to generate new insights in support of the fight against Covid-19. The dataset contains more than 51,000 scholarly articles on SARS-CoV-2 and related coronaviruses such as SARS-CoV and the Middle East Respiratory Syndrome (MERS) Coronavirus including over 40,000 full texts [14]. Beside these documents, a file containing the publications' metadata, is provided. It contains information such as title, DOI, PubMed ID and the abstract, but is not limited to these. In a first step the metadata is preprocessed and a keyword search is performed to identify publications of interest. Afterwards, the typical literature review procedure is carried out, including screening of title and abstract for eligibility and accessing the full texts.

For preprocessing of the data, a simple algorithmic pipeline was applied to the metadata file. First, information of interest (PubMed ID, title, abstract, availability of the full text) are extracted. In the next steps, all articles without a full text, with abstracts shorter than 20 words and with abstracts in a different language than English are excluded. Afterwards, the abstracts and keywords are transformed to lower case characters to perform an algorithmic keyword search analog to the above-mentioned search term. The search was performed on 25.03.2020 and updated on 21.04.2020.

\section{Analytical methods}

In a first step the identified publications' titles and abstracts are screened for eligibility. For publications describing literature reviews or meta-studies, the references are checked for eligibility. Full texts of suitable publications are then analyzed regarding the inclusion criteria. Both steps were executed by multiple researchers.

The analysis centers on the identification of risk factors for severe and fatal disease progression. Risk factors found are categorized into lifestyle factors, demographic factors, pre-existing comorbidities, due to Covid-19 developed comorbidities, symptoms and clinical factors. Additionally, information on the studies are extracted including study size, location, duration, mono- or multicentricity and 
whether the data collected is available. For characterization of the articles, the publication status is recorded. To ensure the quality of preprints, the comprehensibility and correctness of the study design and statistical analysis is evaluated. In the event of uncertainty, the decision is to exclude the record. P-values smaller than 0.05 are regarded as significant.

\section{Results}

In the search 213 papers were identified (67 PubMed, 131 CORD, 15 referenced literature). After the removal of duplicates 204 records were screened based on title and abstract. In this step, 125 records were excluded. The remaining records' full texts were assessed and 51 records were excluded for not describing risk factors backed by a clinical study or not diagnosing patients by rt-PCR. Thus 28 records were included (see Fig. 1).

Table 1 shows a description of the studies found in the records included. From the 28 included records 17 are published and 11 are preprints. The studies described took place at the end of 2019 and in the first months of 2020. The last inclusion of a patient was on 05.04.2020 in [40]. Most studies found were conducted in China $(n=24)$, while the remaining five studies were conducted in Italy, France and the USA (see Fig. 2). Eighteen studies were carried out at a single place, while twelve studies were multicentric, involving between 2 and 575 hospitals. The patient numbers of the individual studies range between 25 and 62,843 , with small studies with up to 200 patients being the norm.

\section{Risk factors for severity}

Risk factors for disease severity were identified in 20 records, which are described in Table 2. Smoking [33], a higher body mass index (obesity) [40] and a longer waiting time to hospital admission $[19,20]$ are lifestyle factors related to a higher risk for disease severity. The most frequently mentioned demographic factor increasing the risk for a severe course of disease is higher age $[16,17,19,21$, $27,30,31,33,35,41,42]$, followed by male gender [19, $21,25]$, post menopausality [25] and higher age in females [25]. Some publications specify the age for increased risk as $>64$ [31] or $>65$ [33] years. The most common pre-existing comorbidities are hypertension [16, 19, 27, 35, 40, 42] and diabetes $[16,28,33,35,40,42]$ with six records each, followed by cardiovascular disease with three records $[16$,
Fig. 1 Overview of the publication selection process

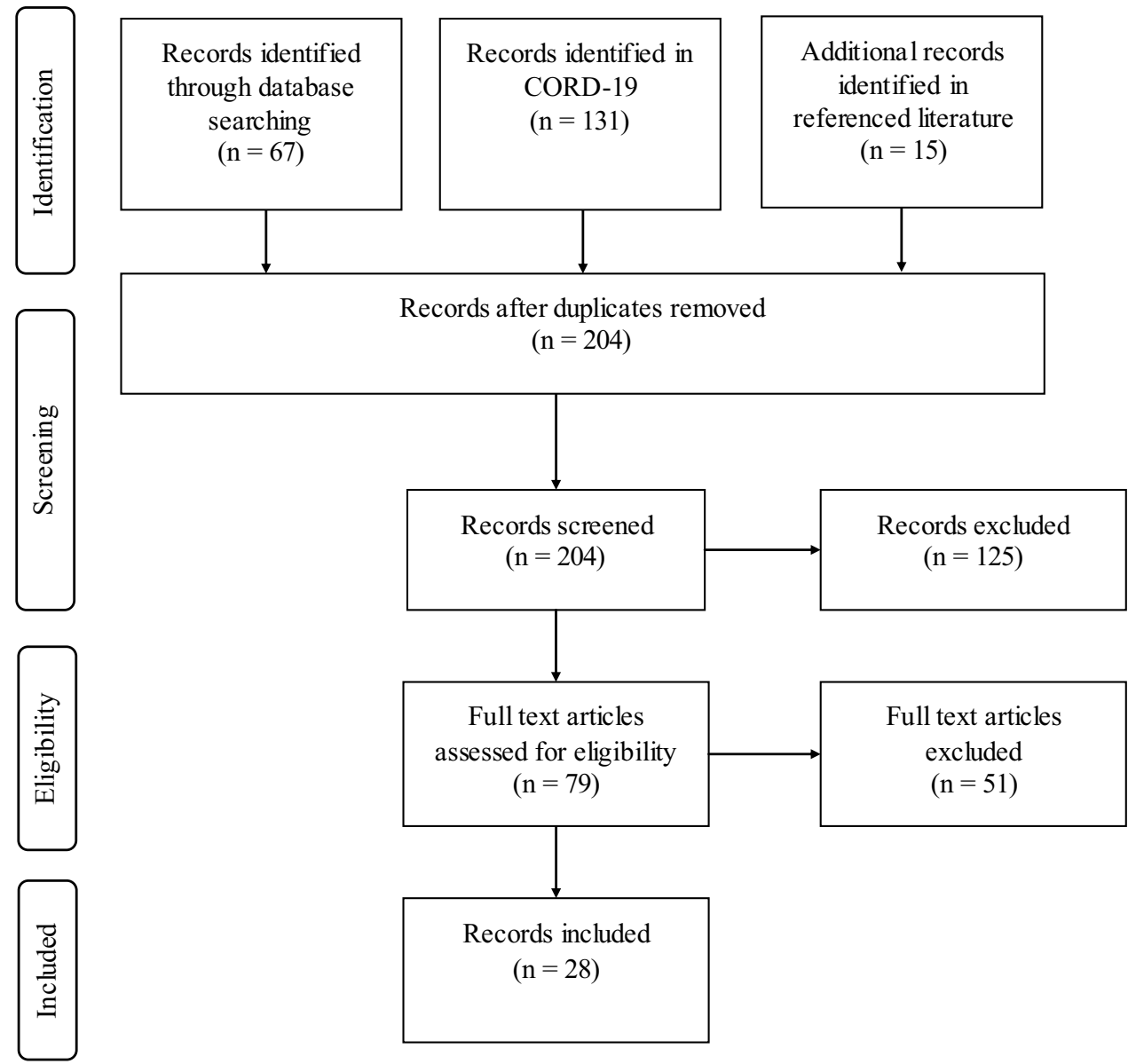


Table 1 Overview of the records included

\begin{tabular}{|c|c|c|c|c|c|c|}
\hline Reference & Review state & Study size & Study location & $\begin{array}{l}\text { Centricity (\# of cent- } \\
\text { ers) }\end{array}$ & Study duration & Data published \\
\hline [15] & Published & 25 & Wuhan, China & Monocentric & $\begin{array}{r}14.01 .2020- \\
13.02 .2020\end{array}$ & Data published \\
\hline [16] & Published & 138 & Wuhan, China & Monocentric & $\begin{array}{r}01.01 .2020- \\
28.01 .2020\end{array}$ & Synoptic table \\
\hline$[17]$ & Published & 140 & Wuhan, China & Monocentric & $\begin{array}{r}16.01 .2020- \\
03.02 .2020\end{array}$ & Synoptic table \\
\hline [18] & $\begin{array}{l}\text { Preprint, not peer } \\
\text { reviewed }\end{array}$ & 128 & Xiangyang, China & Monocentric & $\begin{array}{r}01.01 .2020- \\
16.02 .2020\end{array}$ & Synoptic table \\
\hline [19] & $\begin{array}{l}\text { Preprint, not peer } \\
\text { reviewed }\end{array}$ & 198 & Shanghai, China & Monocentric & $\begin{array}{r}20.01 .2020- \\
15.02 .2020\end{array}$ & Full dataset on request \\
\hline [20] & $\begin{array}{l}\text { Preprint, not peer } \\
\text { reviewed }\end{array}$ & 141 & Changsha, China & Multicentric (2) & $\begin{array}{r}17.01 .2020- \\
01.02 .2020\end{array}$ & Synoptic table \\
\hline$[21]$ & Published & $43 ; 1056$ & Wuhan, China & $\begin{array}{l}\text { Mono-, multicentric } \\
\text { (6) }\end{array}$ & $\begin{array}{r}29.01 .2020- \\
15.02 .2020\end{array}$ & Full dataset on request \\
\hline$[22]$ & $\begin{array}{l}\text { Preprint, not peer } \\
\text { reviewed }\end{array}$ & 710 & Wuhan, China & Multicentric (3) & $\begin{array}{r}28.01 .2020- \\
11.02 .2020\end{array}$ & Synoptic table \\
\hline$[23]$ & Published & 383 & Wuhan, China & Monocentric & $\begin{array}{r}02.01 .2020- \\
01.03 .2020\end{array}$ & Synoptic table \\
\hline$[24]$ & Published & 245 & Wuhan, China & Monocentric & $\begin{array}{r}01.01 .2020- \\
29.02 .2020\end{array}$ & Synoptic table \\
\hline$[25]$ & $\begin{array}{l}\text { Preprint, not peer } \\
\text { reviewed }\end{array}$ & 1902 & Wuhan, China & Multicentric (3) & $\begin{array}{r}28.01 .2020- \\
08.03 .2020\end{array}$ & Synoptic table \\
\hline$[26]$ & $\begin{array}{l}\text { Preprint, not peer } \\
\text { reviewed }\end{array}$ & 355 & $\begin{array}{l}\text { Wuhan, China } \\
\text { Fuyang, China }\end{array}$ & Multicentric (2) & $?$ & Synoptic table \\
\hline$[27]$ & Published & 54 & Stanford, USA & Monocentric & Until 16.03.2020 & Full dataset on request \\
\hline$[28]$ & $\begin{array}{l}\text { Preprint, not peer } \\
\text { reviewed }\end{array}$ & 258 & Wuhan, China & Monocentric & $\begin{array}{r}29.01 .2020- \\
12.02 .2020\end{array}$ & Full dataset on request \\
\hline [29] & $\begin{array}{l}\text { Preprint, not peer } \\
\text { reviewed }\end{array}$ & 84 & Yongchuan, China & Monocentric & $\begin{array}{r}21.01 .2020- \\
02.03 .2020\end{array}$ & Full dataset on request \\
\hline$[30]$ & $\begin{array}{l}\text { Preprint, not peer } \\
\text { reviewed }\end{array}$ & 62,843 & complete Italy & Multicentric (?) & Until 24.03.2020 & Synoptic table \\
\hline$[31]$ & Published & 4,103 & New York City, USA & Multicentric (4) & $\begin{array}{r}01.03 .2020- \\
01.04 .2020\end{array}$ & Synoptic table \\
\hline$[32]$ & Published & 701 & Wuhan, China & Monocentric & $\begin{array}{r}28.01 .2020- \\
11.02 .2020\end{array}$ & Full dataset on request \\
\hline$[33]$ & Published & 323 & Wuhan, China & Monocentric & $\begin{array}{r}08.01 .2020- \\
20.02 .2020\end{array}$ & Synoptic table \\
\hline$[34]$ & Published & 1590 & complete China & Multicentric (575) & Until 31.01.2020 & Synoptic table \\
\hline$[35]$ & $\begin{array}{l}\text { Preprint, not peer } \\
\text { reviewed }\end{array}$ & 564 & Hunan, China & Multicentric (9) & $\begin{array}{r}17.01 .2020- \\
28.02 .2020\end{array}$ & Full dataset on request \\
\hline$[36]$ & $\begin{array}{l}\text { Preprint, not peer } \\
\text { reviewed }\end{array}$ & 36 & Shenyang, China & Multicentric (3) & $\begin{array}{r}26.01 .2020- \\
15.02 .2020\end{array}$ & Synoptic table \\
\hline$[37]$ & Published & 52 & Wuhan, China & Monocentric & 12.2019-26.01.2020 & Full dataset on request \\
\hline$[38]$ & Published & 54 & Hubei, China & Monocentric & $?$ & Synoptic table \\
\hline [39] & Published & 1591 & Lombardy, Italy & Multicentric (72) & $\begin{array}{r}20.02 .2020- \\
18.03 .2020\end{array}$ & Synoptic table \\
\hline$[40]$ & Published & 124 & Lille, France & Monocentric & $\begin{array}{r}27.02 .2020- \\
05.04 .2020\end{array}$ & Synoptic table \\
\hline$[41]$ & Published & 30 & Huizhou, China & Monocentric & $01.2020-02.2020$ & Synoptic table \\
\hline [42] & Published & 174 & Wuhan, China & Monocentric & $\begin{array}{r}10.02 .2020- \\
29.02 .2020\end{array}$ & Synoptic table \\
\hline
\end{tabular}




\section{study locations}

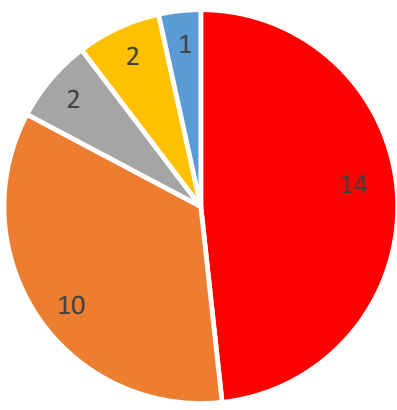

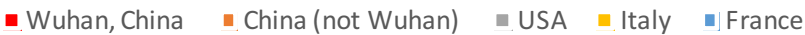

Fig. 2 Number of studies found by location

19, 35]. Occasionally, correlations of the severity and cerebrovascular disease [16], chronic obstructive pulmonary disease [35], chronic renal disease [35] or tuberculosis [36] were found. For eight comorbidities developed during the Covid-19 infection a significant impact on disease severity was found. These are organ failure [19], immunological dysfunction [19], acute liver injury [26], hypoproteinemia [26], Acute Respiratory Distress Syndrome (ARDS) [36], severe pneumonia [42], uncontrolled inflammation response [42] and hypercoagulable state [42]. With nine mentions, the most common abnormal clinical factor is decreased lymphocytes, followed by an increased D-dimer level (six records), increased leucocytes (four records), increased neutrophil count (four records), increased aspartate aminotransferase (AST) (four records), increased c-reactive protein (CRP) (four records), increased alanine aminotransferase (ALT) (three records) and low oxygen saturation (three records). Increased blood urea nitrogen (BUN), decreased thrombocytes, increased CT severity score and increased interleukin 6 (IL-6) level are each identified as risk factors for severity in two records. There are 23 other clinical features such as decreased blood sodium or decreased erythrocytes count each mentioned in one record only (see Table 2 ). In addition to the factors already mentioned, the symptoms fever $\left(>38.5^{\circ} \mathrm{C}\right)[18,35]$ and dyspnea $[18,35]$ are associated with severe disease progression.

\section{Risk factors of fatal disease courses}

Thirteen records describe risk factors for fatal Covid-19 disease courses. They are listed in Table 3 . The most common identified risk factor is high age with eight denominations. The other demographic factor influencing Covid-19 mortality is male gender, which was found significant in three records. Furthermore, pre-existing comorbidities frequently show an influence in the publications included. Most common with three mentions each are hypertension, diabetes and coronary heart disease. Cardiovascular diseases are found significant in two records. Seven other pre-existing diseases were each significant in one record, including acute liver injury, kidney disease, chronic illnesses and cerebrovascular disease. For comorbidities developed during the infection, kidney injuries (four records), heart injuries (three records) and liver injuries (two records) are mentioned most often. Other developed complications are cardiac death, acute respiratory distress syndrome, hospital acquired infections, thrombocytopenia and hypoxemia. Only one record identified a symptom, dyspnea, as a risk factor. The most common clinical factors associated with mortality are increased creatinine (four records), increased c-reactive protein (CRP), increased procalcitonin (PCT), decreased lymphocytes and increased blood urea nitrogen (BUN) (three records each). Other clinical factors associated with fatal disease courses include increased neutrophils, increased leucocytes or increased D-dimer but are not limited to these. For the full list of clinical factors found in the records please refer to Table 3.

Typically, a severe course of the disease occurs before the death of a Covid-19 patient. Of course, this is not true for all fatal courses, but it should be true for most of them and therefore be visible in the statistical significance. The risk factors for fatal courses should be approximately a subset of the factors for severe courses. Therefore, risk factors for fatal disease progression, which are not mentioned for severe disease progression, are of particular interest. For pre-existing comorbidities these are coronary heart disease, hypoproteinemia, cholestasis, acute liver injury and hypercholesterolemia, while hypoproteinemia and acute liver injury are also mentioned as developed comorbidities in severe courses. Developed comorbidities found with an influence on fatal courses but not on severe courses are heart damage, kidney damage, thrombocytopenia, hospital acquired infections, hypoxemia and cardiac death.

\section{Disease specific laboratory values}

Some laboratory values found are predictive for specific diseases. Most common are markers for liver, renal and heart function. Increased ALT, AST, lactic acid, procalcitonin, total, direct and indirect bilirubin as well as decreased albumin indicate liver injuries [43]. The same applies for increased blood urea nitrogen and creatinine as well as proteinuria and hematuria for renal injuries [44]. Heart specific markers found in the publications are increased creatine kinase, troponin $\mathrm{C}$ and myohemoglobin levels as well as a decreased platelet count [45]. It is also noticeable that an increased number of coagulation factors such as decreased platelets, increased D-dimer level and increased fibrinogen 
Table 2 (continued)

Reference Lifestyle factors

Preexisting comorbidities to admission

[21]

[25]

[30]

[31]
Higher age

Hypertension

Higher age

Male gender

Post-menopausality

Higher age of

females

Male gender

Higher age

Hypertension

Diabetes

Higher age

Higher age

Age $>64$

Age $>65$

Diabetes

Developed comor- $\quad$ Clinical factors
bidities
bidities

Decreased lympho-

cyte count

Increased neutrophilto-lymphocyte ratio (NLR)

Increased C-reactive protein

Increased CT sever-

ity score

Increased Interleu-

kin 6

Increased Interleu-

kin 8

E2 and AMH are

negatively cor-

related

Acute liver injury

Hypoproteinemia

Elevated total bilirubin, elevated direct bilirubin

Elevated indirect

bilirubin,

Elevated ALT

Elevated AST

Decreased total

protein

Decreased albumin

Decreased albumin per globulin ratio

Low presenting oxygen saturation

Admission oxygen saturation $<88 \%$

first D-dimer $>250$

First C-reactive

protein $>200$

SpO2 $<88$

Procalcitonin $>0.5$

Troponin $<0.1$

C-reactive pro-

tein $>200$

Abnormally higher hypersensitive troponin I ( $>0.04 \mathrm{pg}$ / $\mathrm{mL}$ )

Leucocyte count $>10 \times 10^{9} / \mathrm{L}$ neutrophil

count $>75 \times 10^{9} / \mathrm{L}$ 
Table 2 (continued)

\begin{tabular}{|c|c|c|c|c|c|c|}
\hline Reference & Lifestyle factors & Demographic factors & $\begin{array}{l}\text { Preexisting comor- } \\
\text { bidities }\end{array}$ & $\begin{array}{l}\text { Developed comor- } \\
\text { bidities }\end{array}$ & Clinical factors & Symptoms \\
\hline [35] & & Higher age & $\begin{array}{l}\text { Hypertension } \\
\text { Diabetes } \\
\text { Cardiovascular } \\
\text { disease } \\
\text { Chronic obstructive } \\
\text { pulmonary disease } \\
\text { Chronic renal disease }\end{array}$ & & $\begin{array}{l}\text { Increased aspartate } \\
\text { aminotransferase } \\
\text { Increased blood urea } \\
\text { nitrogen } \\
\text { D-dimer } \geq 0.05 \mathrm{mg} / \mathrm{L} \\
\text { Increased lactose } \\
\text { dehydrogenase } \\
\text { Worse lung CT score } \\
\text { Decreased lympho- } \\
\text { cyte count }\end{array}$ & $\begin{array}{l}\text { Presented with } \\
\text { fever } \\
\text { Presented with } \\
\text { shortness of } \\
\text { breath }\end{array}$ \\
\hline [36] & & & Tuberculosis & $\begin{array}{l}\text { Acute respiratory } \\
\text { distress syndrome }\end{array}$ & & \\
\hline [37] & & & & & Lymphocytopenia & \\
\hline [40] & Higher BMI & & $\begin{array}{l}\text { Diabetes and hyper- } \\
\text { tension (dependent } \\
\text { with obesity) }\end{array}$ & & $\begin{array}{l}\text { Decreased blood } \\
\text { oxygen saturation } \\
\text { Need for oxygen sup- } \\
\text { port therapy for at } \\
\text { least } 6 \mathrm{~L} / \mathrm{min}\end{array}$ & \\
\hline [41] & & Higher age & & & $\begin{array}{l}\text { Increased platelet-to- } \\
\text { lymphocyte ratio at } \\
\text { platelet peak } \\
\text { Decreased lympho- } \\
\text { cyte count } \\
\text { Higher platelet peak }\end{array}$ & \\
\hline [42] & & Higher age & $\begin{array}{l}\text { Diabetes } \\
\text { Hypertension }\end{array}$ & $\begin{array}{l}\text { Severe pneumonia } \\
\text { Uncontrolled inflam- } \\
\text { mation responses } \\
\text { Hypercoagulable } \\
\text { state }\end{array}$ & $\begin{array}{l}\text { Elevated Interleu- } \\
\text { kin } 6 \\
\text { Elevated C-reactive } \\
\text { protein } \\
\text { Elevated serum } \\
\text { ferritin } \\
\text { Elevated coagulation } \\
\text { index } \\
\text { Elevated D-dimer } \\
\text { Decreased count of } \\
\text { lymphocytes } \\
\text { Higher absolute } \\
\text { count of neutro- } \\
\text { phils } \\
\text { Decreased erythro- } \\
\text { cytes counts } \\
\text { Decreased hemo- } \\
\text { globin }\end{array}$ & \\
\hline
\end{tabular}

[46] as well as inflammatory parameters such as c-reactive protein [47] and increased leucocyte level are associated with severity and fatality.

\section{Discussion}

This review shows a high exclusion rate (176/204), which is mainly caused by including studies identifying Covid19 infections explicitly by rt-PCR only. However, a high significance of the results can be guaranteed, as other diseases, such as bacterial pneumonia, are clearly excluded by the rt-PCR identification. Identification by rt-PCR has also become the standard diagnostic procedure. Nevertheless, it must be assumed that a selection bias exists in the results obtained, since most studies do not provide a representative sample. Among other things, differences in the recruitment rate and different test procedures have an influence on this. Relying on rt-PCR based studies only enhances this effect. A portion of the included papers are preprints, which were not yet peer-reviewed. This allows early scientific results to be incorporated into the analysis performed in this record. Even though a quality review by the authors has been carried out, which includes the comprehensibility and correctness of the study design as well as the statistical analysis, the results of these preprinted studies should be used with caution in 
Table 3 Listing of the factors found with an influence on fatal disease courses

Reference Lifestyle factors Demographic factors Preexisting comorbidi-

Developed comorbidities Clinical factors

Symptoms ties

[15]

[23]
Higher age

Male gender

Age $>65$ years

Hypertension

Diabetes

Coronary heart disease

Hypoproteinemia

Cholestasis

Acute liver injury

Diabetes

Higher age

Male gender
Heart damage

Kidney damage

Liver damage

Kidney impairment

Thrombocytopenia

Kidney disease

Acute kidney injury
Decrease albumin

Increased PCT

Increased neutrophils

Increased C-reactive

protein

Increased cTnI

Increased D-Dimer

Increased LHD

Decreased lymphocyte

level

Leucocyte count $>4 \times 10^{9} / \mathrm{L}$

Lymphocyte $<1.5 \times 10^{9} / \mathrm{L}$

Increased serum creatinine baseline

Increased serum creatinine peak Increased blood urea nitrogen (BUN)

Increased proteinuria Increased hematuria

Decreased platelet count (40\% decrease in mortality risk for every $50 \times 10^{9} / \mathrm{L}$ increase)

Dynamic change of platelets

Neutrophil to lymphocyte ratio (NLR)

$8 \%$ higher risk per unit increase

Respiratory rate $>30 \mathrm{bpm}$ Increased neutrophil Increased ALT Increased creatinine Increased prothrombin Increased C-reactive protein Increased procalcitonin CT abnormalities Patchy shadows Ground glass opacities Consolidation Interlobular septal thickening

Higher CT value
Elevated baseline serum creatinine

Elevated baseline blood urea nitrogen (BUN)

Proteinuria

Hematuria 
Table 3 (continued)

\begin{tabular}{|c|c|c|c|c|c|}
\hline Reference Lifestyle factors & Demographic factors & $\begin{array}{l}\text { Preexisting comorbidi- } \\
\text { ties }\end{array}$ & Developed comorbidities & Clinical factors & Symptoms \\
\hline$[34]$ & Age $>65$ & $\begin{array}{l}\text { Coronary heart } \mathrm{f} \\
\text { Disease } \\
\text { Cardiovascular disease }\end{array}$ & & $\begin{array}{l}\mathrm{PCT}>0.5 \mathrm{ng} / \mathrm{ml} \\
\mathrm{AST}>40 \mathrm{U} / 1\end{array}$ & Dyspnea \\
\hline [37] & Higher age & $\begin{array}{l}\text { Chronic illness } \\
\text { Cerebrovascular disease }\end{array}$ & $\begin{array}{l}\text { Acute Respiratory Dis- } \\
\text { tress Syndrome } \\
\text { Hospital acquired infec- } \\
\text { tion } \\
\text { organ function damage } \\
\text { (kidney, cardiac, liver) } \\
\text { Hypoxemia }\end{array}$ & $\begin{array}{l}\text { Low ratio partial pres- } \\
\text { sure oxygen }\left(\mathrm{PaO}_{2}\right) \text { to } \\
\mathrm{F}_{\mathrm{i}} \mathrm{O}_{2}\end{array}$ & \\
\hline$[38]$ & Higher age & $\begin{array}{l}\text { Hypertension } \\
\text { Coronary heart disease }\end{array}$ & $\begin{array}{l}\text { Heart injury } \\
\text { Cardiac death }\end{array}$ & $\begin{array}{l}\text { Increased NT-proBNP } \\
\text { Increased myohemo- } \\
\text { globin } \\
\text { Increased CK-MB } \\
\text { Increased hs-TnI } \\
\text { Increased blood urea } \\
\text { Increased creatinine } \\
\text { Increased white blood } \\
\text { cell count } \\
\text { Increased CRP } \\
\text { Increased procalcitonin } \\
\text { Decreased lymphocyte } \\
\text { Higher diastolic blood } \\
\text { pressure }\end{array}$ & \\
\hline [39] & $\begin{array}{l}\text { Higher age } \\
\text { Male gender }\end{array}$ & $\begin{array}{l}\text { Hypertension } \\
\text { Cardiovascular disease } \\
\text { Hypercholesterolemia } \\
\text { Diabetes }\end{array}$ & & & \\
\hline
\end{tabular}

further decisions concerning Covid-19. The publication status of the preprints should be reviewed at a later date.

Most records included describe studies carried out in China. This is presumably since the disease first broke out in China and spread around the world only within the next weeks and months. Data from Chinese Covid-19 patients is available earlier and can therefore be analyzed and published earlier. When comparing the data on the level of the number of patients or facilities, a different picture arises. The majority of patients included in this review are from Italy $(64,434)$, followed by China (7656), USA (4157) and France (1715). Therefore, statements for specific ethnicity cannot be made and the results should be generally interpreted. It should be noted that a doubling of patients between studies cannot be excluded. This is especially relevant for some of the Chinese publications, which show an overlapping of the author list and the recruitment time, potentially reducing the real number of patients. Based on the number of publications and the number of patients, it seems that Italy is trying to centralize research on Covid-19, while China tends to produce smaller individual studies. Both approaches have advantages and disadvantages. Individual studies can deliver results more quickly and be transferred to the community, while centralization allows linking the data so that statements of higher quality can be made. The rather small proportion of studies from the USA and Europe could be linked to the date the search was carried out and the course of the disease's global spread. We expect to see more studies from these countries as well as other Asian countries in the future. Concerning the number of patients, publication [30] is particularly noteworthy as it summarizes all cases in Italy until the beginning of March. Unfortunately, the data of this study are not published as a complete data set. However, the publication rate of the collected data is quite high among the studies included as data of eight studies is publicly available or available upon request.

Since no special drug for treating Covid-19 exists, a longer waiting time to hospital admission is an eye-catching risk factor for severity. This indicates that the treatment of symptoms in an early disease stage can be effective and positively influence the disease's course. Regarding other demographic and lifestyle factors found interdependencies are very likely. First, younger women will not be menopausal and therefore post menopausality is equivalent to higher age, which is the most named risk factor in this analysis. Second, with higher age comorbidities are getting more likely to be present while the immune systems is getting weaker [48]. This means higher age (approximately $>60$ years) is very 
likely correlated with comorbidities such as hypertension, cardiovascular diseases and diabetes, which are the most common comorbidities in this review. Third, hypertension is a risk factor for cardiovascular diseases [49] and, since cardiovascular disease appear to be a risk factor for Covid-19, hypertension is a risk factor for Covid-19 as well. Although multivariate regression analyses are performed in 16 records, those dependencies could not be confirmed. More research and testing on interdependence of risk factors should to be carried out.

Typically, for a disease that primarily affects the lungs, it would be expected that lung-damaging behaviors, such as smoking, or pre-existing lung diseases increase the risk for severe courses. It is very striking that smoking shows a significant influence in only one publication as well as lung diseases not being commonly listed as risk factors for either severe or fatal disease progression. This may be related to the fact that the definition of a severe disease course is based on severe pneumonia and is therefore not listed. However, other pre-existing lung diseases such as chronic obstructive pulmonary disease (COPD) are only named in a few records. For nicotine on the other hand the ability to downregulate the ACE-2 level, which is a functional receptor for SARSCoV-2 [1], was shown [50]. Furthermore, a mouse study [51] suggests that nicotine protects against acute inflammation in lung tissue by activating nicotinic acetylcholine receptors on immune cells which inhibits the release of proinflammatory cytokines. However, nicotine's influence on the course of Covid-19 needs further research.

Regarding disease predictive clinical factors liver, renal and heart damage are most common, which are also present as comorbidities associated with increased risk. It can be assumed that Covid-19 damages these organs and pre-existing damages further promote the impact. Eleven records found coagulation factors positively associated with severity or fatality but only two ([23] and [42]) mention them directly in the publication. Therefore, the influence of coagulation disorders and their treatments on the course of the disease should be further examined. It is also possible that the above-mentioned organ damage is promoted or triggered by Covid-19 induced coagulation disorders. A newer pathological study with twelve deceased Covid-19 patients found high incidence of thromboembolic events suggesting an important role of Covid-19 - induced coagulopathy. Even more, 5 of the 12 patients showed high viral RNA titers in the liver, kidney, or heart [52]. In addition, laboratory values indicating heart, liver and renal damages are significant in the included records for fatal disease courses but not for severe ones. This suggests that organ damages, specifically heart, kidney and liver damages, are symptoms occurring in the late phase of Covid-19 infections.

For some risk factors found, it cannot be entirely excluded that they are manifestations of the disease itself and not real risk factors. This is especially the case for risk factors that are very close to the clinical picture of Covid-19, such as low oxygen saturation or ARDS. For cardinal symptoms of a severe disease, statistical significance is very likely to be found. Even if a significant influence on the severity of the disease has been found in several studies, it must be understood that causality does not necessarily follow from statistical significance.

Still, there are limitations to this review. Due to the exclusive focus on PCR diagnostics it is possible that some important factors are dismissed, which were found in studies relying on clinical diagnostics. However, the focus on PCR diagnosis increases the recall and hence the results' expressiveness. Furthermore, records in which significant influencing factors for the severity or fatality are shown, but which are not called risk factors in the title or abstract, cannot be identified by the search strategy. An example of this is [53]. It must be assumed that other risk factors for serious and fatal injuries and publications on them exist which are not covered in this review. The studies found only took place in four countries meaning ethnic differences in the course of the disease cannot be considered. A certain bias can also arise from the timing of the search. The search was last updated on 21.04.2020, so that rather early publications are to be expected.

\section{Comparison with official sites}

Table 4 shows the risk factors for severe disease courses form different public authorities. The Robert Koch Institute is Germany's leading Public Health facility, whereas the Johns Hopkins University is one of the world's leading facilities for Covid-19 updates. Furthermore, risk factors declared by the United States' Centers for Disease Control and Prevention and the National Health Service of the United Kingdom are shown. The lists of the different institutions largely overlap. High age (from about 60 years), heart, renal, liver and respiratory diseases as well as diabetes and obesity are frequently mentioned factors. Other factors mentioned include immune compression, male sex, organ receptivity, pregnancy, smoking, secondary diseases, such as cancer or conditions affecting the brain or nerves, and African American ethnicity.

On the most frequently mentioned points, the risk factors indicated by public authorities coincide with the results of the review. These are liver, heart, renal and respiratory diseases as well as diabetes, obesity, higher age, male gender, comorbidities and even conditions affecting brain and nerves. Risk factors mentioned by public authorities which were not present in this review include multimorbidity, immunosuppression, being an organ transplant recipient, asthma, living in a nursing home, African American ethnicity, blood or bone cancer as well as pregnancy. Even if 
Table 4 Overview of risk factors reported by leading institutions

\begin{tabular}{llll}
\hline Robert Koch Institute [54] & U.S. CDC [55] & Johns Hopkins Medicine [56] & NHS UK [57] \\
\hline $\begin{array}{lll}\text { Higher age (increase from } \\
\text { 50-60 years) }\end{array}$ & Higher age (increase from 65 years) & Higher age (increase from 65 years) & $\begin{array}{c}\text { Higher age (increase from } \\
\text { Heart diseases }\end{array}$ \\
$\begin{array}{llll}\text { Living in a nursing home or long- } \\
\text { term care facility }\end{array}$ & Diabetes & Organ transplant recipients \\
Diabetes & Chronic lung disease & Male gender & Lung diseases \\
Diseases of the respiratory system & Asthma & USA: obesity (BMI $\geq 30)$ & Blood or bone marrow cancer \\
Liver diseases & Heart diseases & USA: African American ethnicity & Heart diseases \\
Renal diseases & Immunosuppression & Comorbidities & Pregnancy \\
Obesity & Severe obesity (BMI $\geq 40)$ & & Severe obesity (BMI $\geq 40)$ \\
Smoking & Diabetes & & Chronic kidney diseases \\
Multimorbidity & Chronic kidney disease undergoing & & Conditions affecting brain or \\
& dialysis & nerves
\end{tabular}

these could not be confirmed by the review, most of them seem to be very reasonable. Conditions resulting in a diminished immune system such as cancer, immunosuppression or being an organ transplant recipient weaken the body's own immune response to SARS-CoV-2. Another factor is expected to be the prevalent viral pressure, which is high in places where many partly immune-deficient people share little space such as nursing homes. Although studies from the USA were included, no justification for African American ethnicity being a risk factor was found in this review.

This review identified some risk factors not mentioned by public authorities. Mostly these are waiting time to hospital admission, tuberculosis, inflammation disorders and coagulation factors. It is possible that for these factors, especially coagulation factors, not enough evidence is present yet to be support by public authorities.

\section{Conclusion}

Most of the 28 records included in this review describe studies conducted in China. However, regarding the number of patients Italy is outstanding. Conditions and comorbidities potentially connected to a poor state of health such as high age, obesity, diabetes and hypertension were identified as risk factors for severe and fatal disease courses. It was found that severe and even more fatal courses of disease are associated with organ damages mainly affecting the heart, the liver and the kidneys. Further, inflammation and coagulation dysfunctionality were identified as risk factors. For coagulation factors, laboratory values were significantly different in Covid-19 patients but were mostly not mentioned as risk factors in the records' texts. A prospective study with 12 deceased Covid-19 patients supports this finding. Therefore, the influence of coagulation disorders developed during a SARS-CoV-2 infection should be further investigated.
Author contributions All authors contributed to the study conception and design. Material preparation, data collection and analysis were performed by DW, SN and NSH. The first draft of the manuscript was written by DW and all authors commented on previous versions of the manuscript. All authors read and approved the final manuscript.

Funding Open Access funding provided by Projekt DEAL. The authors declare that no funding was received for the review.

Data availability All data used is publicly available either by PubMed or CORD-19.

Code availability The python code used for preprocessing and search in CORD-19 will be made available upon request.

\section{Compliance with ethical standards}

Conflict of interest The authors declare that there is no conflict of interest.

Open Access This article is licensed under a Creative Commons Attribution 4.0 International License, which permits use, sharing, adaptation, distribution and reproduction in any medium or format, as long as you give appropriate credit to the original author(s) and the source, provide a link to the Creative Commons licence, and indicate if changes were made. The images or other third party material in this article are included in the article's Creative Commons licence, unless indicated otherwise in a credit line to the material. If material is not included in the article's Creative Commons licence and your intended use is not permitted by statutory regulation or exceeds the permitted use, you will need to obtain permission directly from the copyright holder. To view a copy of this licence, visit http://creativecommons.org/licenses/by/4.0/.

\section{References}

1. Lu R, Zhao X, Li J, Niu P, Yang B, Wu H, et al. Genomic characterisation and epidemiology of 2019 novel coronavirus: implications for virus origins and receptor binding. Lancet. 2020;395:565-74. https://doi.org/10.1016/S0140-6736(20)30251 -8 . 
2. World Health Organization. WHO best practices for naming of new human infectious diseases. 2015. https://www.who.int/topic s/infectious_diseases/naming-new-diseases/en/. Accessed $14 \mathrm{Apr}$ 2020.

3. World Health Organization. Disease outbreak news. 2020. https ://www.who.int/csr/don/05-january-2020-pneumonia-of-unkow n-cause-china/en/. Accessed 15 Apr 2020.

4. TA Ghebreyesus. WHO Director-General's opening remarks at the media briefing on COVID-19-11 March 2020; 2020.

5. Chan JF-W, Yuan S, Kok K-H, To KK-W, Chu H, Yang J, et al. A familial cluster of pneumonia associated with the 2019 novel coronavirus indicating person-to-person transmission: a study of a family cluster. Lancet. 2020;395:514-23. https://doi.org/10.1016/ S0140-6736(20)30154-9.

6. John Hopkins University. COVID-19 Dashboard by the Center for Systems Science and Engineering (CSSE) at Johns Hopkins University (JHU). 2020. https://coronavirus.jhu.edu/map.html. Accessed 14 Apr 2020.

7. Dong E, Du H, Gardner L. An interactive web-based dashboard to track COVID-19 in real time. Lancet Infect Dis. 2020. https ://doi.org/10.1016/S1473-3099(20)30120-1.

8. Corman VM, Landt O, Kaiser M, Molenkamp R, Meijer A, Chu DKW, et al. Detection of 2019 novel coronavirus (2019$\mathrm{nCoV}$ ) by real-time RT-PCR. Euro Surveill. 2020. https://doi. org/10.2807/1560-7917.ES.2020.25.3.2000045.

9. Li X, Geng M, Peng Y, Meng L, Lu S. Molecular immune pathogenesis and diagnosis of COVID-19. J Pharm Anal. 2020. https://doi.org/10.1016/j.jpha.2020.03.001.

10. Huang $\mathrm{C}$, Wang Y, Li X, Ren L, Zhao J, Hu Y, et al. Clinical features of patients infected with 2019 novel coronavirus in Wuhan, China. Lancet. 2020;395:497-506. https://doi. org/10.1016/S0140-6736(20)30183-5.

11. Rajgor DD, Lee MH, Archuleta S, Bagdasarian N, Quek SC. The many estimates of the COVID-19 case fatality rate. Lancet Infect Dis. 2020. https://doi.org/10.1016/S1473-3099(20)30244 $-9$.

12. Long C, Xu H, Shen Q, Zhang X, Fan B, Wang C, et al. Diagnosis of the Coronavirus disease (COVID-19): rRT-PCR or CT? Eur J Radiol. 2020;126:108961. https://doi.org/10.1016/j.ejrad .2020.108961.

13. Tahamtan A, Ardebili A. Real-time RT-PCR in COVID-19 detection: issues affecting the results. Expert Rev Mol Diagn. 2020;20:453-4. https://doi.org/10.1080/14737159.2020.1757437.

14. Allen Institute for AI. COVID-19 Open Research Dataset (CORD19). 2020. https://pages.semanticscholar.org/coronavirus-research. Accessed 15 Apr 2020.

15. Li X, Wang L, Yan S, Yang F, Xiang L, Zhu J, et al. Clinical characteristics of 25 death cases with COVID-19: a retrospective review of medical records in a single medical center, Wuhan, China. Int J Infect Dis. 2020. https://doi.org/10.1016/j. ijid.2020.03.053.

16. Wang D, Hu B, Hu C, Zhu F, Liu X, Zhang J, et al. Clinical characteristics of 138 hospitalized patients with 2019 novel coronavirus-infected pneumonia in Wuhan, China. JAMA. 2020. https:// doi.org/10.1001/jama.2020.1585.

17. Zhang J-J, Dong X, Cao Y-Y, Yuan Y-D, Yang Y-B, Yan Y-Q, et al. Clinical characteristics of 140 patients infected with SARSCoV-2 in Wuhan, China. Allergy. 2020. https://doi.org/10.1111/ all.14238.

18. Cao W. Clinical features and laboratory inspection of novel coronavirus pneumonia (COVID-19) in Xiangyang, Hubei; 2020.

19. Cao M, Zhang D, Wang Y, Lu Y, Zhu X, Li Y, et al. Clinical features of patients infected with the 2019 novel coronavirus (COVID-19) in Shanghai, China; 2020.
20. Feng Z, Yu Q, Yao S, Luo L, Duan J, Yan Z, et al. Early prediction of disease progression in 2019 novel coronavirus pneumonia patients outside Wuhan with CT and clinical characteristics; 2020.

21. Jin J-M, Bai P, He W, Wu F, Liu X-F, Han D-M, et al. Gender differences in patients With COVID-19: focus on severity and mortality. Front Public Health. 2020;8:152. https://doi.org/10.3389/ fpubh.2020.00152.

22. Cheng Y, Luo R, Wang K, Zhang M, Wang Z, Dong L, et al. Kidney impairment is associated with in-hospital death of COVID-19 patients; 2020.

23. Liu Y, Sun W, Guo Y, Chen L, Zhang L, Zhao S, et al. Association between platelet parameters and mortality in coronavirus disease 2019: retrospective cohort study. Platelets. 2020. https:// doi.org/10.1080/09537104.2020.1754383.

24. Liu Y, Du X, Chen J, Jin Y, Peng L, Wang HHX, et al. Neutrophilto-lymphocyte ratio as an independent risk factor for mortality in hospitalized patients with COVID-19. J Infect. 2020. https://doi. org/10.1016/j.jinf.2020.04.002.

25. Ding T, Zhang J, Wang T, Cui P, Chen Z, Jiang J, et al. A Multihospital Study in Wuhan, China: protective effects of non-menopause and female hormones on SARS-CoV-2 infection; 2020.

26. Fu L, Fei J, Xu S, Xiang H-X, Xiang Y, Tan Z-X, et al. Acute liver injury and its association with death risk of patients with COVID19: a hospital-based prospective case-cohort study; 2020.

27. Rubin SJS, Falkson SR, Degner N, Blish C. Clinical characteristics associated with COVID-19 severity in California. J Clin Trans Sci. 2020. https://doi.org/10.1017/cts.2020.40.

28. Zhang Y, Cui Y, Shen M, Zhang J, Liu B, Dai M, et al. Comorbid diabetes mellitus was associated with poorer prognosis in patients with COVID-19: a retrospective cohort study; 2020.

29. Ma K-L, Liu Z-H, Cao C-f, Liu M-K, Liao J, Zou J-B, et al. COVID-19 myocarditis and severity factors: an adult cohort study; 2020.

30. Riccardo F, Ajelli M, Andrianou X, Bella A, Del Manso M, Fabiani M, et al. Epidemiological characteristics of COVID-19 cases in Italy and estimates of the reproductive numbers one month into the epidemic; 2020.

31. Petrilli CM, Jones SA, Yang J, Rajagopalan H, O'Donnell L, Chernyak Y, et al. Factors associated with hospital admission and critical illness among 5279 people with coronavirus disease 2019 in New York City: prospective cohort study. BMJ. 2020;369:m1966. https://doi.org/10.1136/bmj.m1966.

32. Cheng Y, Luo R, Wang K, Zhang M, Wang Z, Dong L, et al. Kidney disease is associated with in-hospital death of patients with COVID-19. Kidney Int. 2020;97:829-38. https://doi. org/10.1016/j.kint.2020.03.005.

33. Hu L, Chen S, Fu Y, Gao Z, Long H, Wang J-M, et al. Risk factors associated with clinical outcomes in 323 COVID-19 hospitalized patients in Wuhan, China. Clin Infect Dis. 2020. https://doi. org/10.1093/cid/ciaa539.

34. Chen R, Liang W, Jiang M, Guan W, Zhan C, Wang T, et al. Risk factors of fatal outcome in hospitalized subjects with coronavirus disease 2019 from a nationwide analysis in China. Chest. 2020. https://doi.org/10.1016/j.chest.2020.04.010.

35. Feng Z, Li J, Yao S, Yu Q, Zhou W, Mao X, et al. The use of adjuvant therapy in preventing progression to severe pneumonia in patients with coronavirus disease 2019: a multicenter data analysis; 2020.

36. Liu Y, Bi L, Chen Y, Wang Y, Fleming J, Yu Y, et al. Active or latent tuberculosis increases susceptibility to COVID-19 and disease severity; 2020.

37. Yang X, Yu Y, Xu J, Shu H, Xia JA, Liu H, et al. Clinical course and outcomes of critically ill patients with SARS-CoV-2 pneumonia in Wuhan, China: a single-centered, retrospective, observational study. Lancet Respir Med. 2020. https://doi.org/10.1016/ S2213-2600(20)30079-5. 
38. Gao L, Jiang D, Wen X-S, Cheng X-C, Sun M, He B, et al. Prognostic value of NT-proBNP in patients with severe COVID-19. Respir Res. 2020;21:83. https://doi.org/10.1186/s12931-02001352-w.

39. Grasselli G, Zangrillo A, Zanella A, Antonelli M, Cabrini L, Castelli A, et al. Baseline characteristics and outcomes of 1591 patients infected with SARS-CoV-2 admitted to ICUs of the Lombardy region, Italy. JAMA. 2020. https://doi.org/10.1001/ jama.2020.5394.

40. Simonnet A, Chetboun M, Poissy J, Raverdy V, Noulette J, Duhamel A, et al. High prevalence of obesity in severe acute respiratory syndrome coronavirus-2 (SARS-CoV-2) requiring invasive mechanical ventilation. Obesity (Silver Spring). 2020. https ://doi.org/10.1002/oby.22831.

41. Qu R, Ling Y, Zhang Y-H-Z, Wei L-Y, Chen X, Li X-M, et al. Platelet-to-lymphocyte ratio is associated with prognosis in patients with coronavirus disease-19. J Med Virol. 2020. https:// doi.org/10.1002/jmv.25767.

42. Guo W, Li M, Dong Y, Zhou H, Zhang Z, Tian C, et al. Diabetes is a risk factor for the progression and prognosis of COVID-19. Diabetes Metab Res Rev. 2020. https://doi.org/10.1002/dmrr.3319.

43. Mayo Foundation for Medical Education and Research (MFMER). Liver function tests. 2019. https://www.mayoclinic.org/tests-proce dures/liver-function-tests. Accessed 22 May 2020.

44. Gounden V, Jialal I. StatPearls: renal function tests. Treasure Island (FL); 2020. PMID: 29939598.

45. Jacob R, Khan M. Cardiac biomarkers: what is and what can be. Indian J Cardiovasc Dis Women WINCARS. 2018;3:240-4. https ://doi.org/10.1055/s-0039-1679104.

46. U.S. National Library of Medicine. Coagulation Factor Tests. 2018. https://medlineplus.gov/lab-tests/coagulation-factor-tests/. Accessed 22 May 2020.

47. Mayo Foundation for Medical Education and Research (MFMER). C-reactive protein test. 2017. https://www.mayoclinic.org/tests -procedures/c-reactive-protein-test. Accessed 22 May 2020.

48. Barnett K, Mercer SW, Norbury M, Watt G, Wyke S, Guthrie B. Epidemiology of multimorbidity and implications for health care, research, and medical education: a cross-sectional study. Lancet. 2012;380:37-433. https://doi.org/10.1016/S0140-6736(12)60240 -2 .
49. Ettehad D, Emdin CA, Kiran A, Anderson SG, Callender T, Emberson $\mathrm{J}$, et al. Blood pressure lowering for prevention of cardiovascular disease and death: a systematic review and metaanalysis. Lancet. 2016;387:957-67. https://doi.org/10.1016/S0140 $-6736(15) 01225-8$.

50. Oakes JM, Fuchs RM, Gardner JD, Lazartigues E, Yue X. Nicotine and the renin-angiotensin system. Am J Physiol Regul Integr Comp Physiol. 2018;315:R895-R906. https://doi.org/10.1152/ ajpregu.00099.2018.

51. Mabley J, Gordon S, Pacher P. Nicotine exerts an anti-inflammatory effect in a murine model of acute lung injury. Inflammation. 2011;34:231-7. https://doi.org/10.1007/s10753-010-9228-x.

52. Wichmann D, Sperhake J-P, Lütgehetmann M, Steurer S, Edler C, Heinemann A, et al. Autopsy findings and venous thromboembolism in patients with COVID-19. Ann Intern Med. 2020. https:// doi.org/10.7326/M20-2003.

53. Koker O, Demirkan FG, Kayaalp G, Cakmak F, Tanatar A, Karadag SG, et al. Does immunosuppressive treatment entail an additional risk for children with rheumatic diseases? A surveybased study in the era of COVID-19. Rheumatol Int. 2020. https ://doi.org/10.1007/s00296-020-04663-9.

54. Robert Koch Institut. Informationen und Hilfestellungen für Personen mit einem höheren Risiko für einen schweren COVID19-Krankheitsverlauf. 2020. https://www.rki.de/DE/Content/ InfAZ/N/Neuartiges_Coronavirus/Risikogruppen.html. Accessed 22 May 2020.

55. Centers for Diseases Control and Prevention. People who are at higher risk for severe illness. https://www.cdc.gov/coronaviru s/2019-ncov/need-extra-precautions/people-at-higher-risk.html. Accessed 22 May 2020.

56. John Hopkins Medicine. Coronavirus COVID-19 (SARSCoV-2). 2020. https://www.hopkinsguides.com/hopkins/view/ Johns_Hopkins_ABX_Guide/540747/all/Coronavirus_COVID _19_SARS_CoV_2. Accessed 22 May 2020.

57. NHS UK. Who's at higher risk from coronavirus. 2020. https:// www.nhs.uk/conditions/coronavirus-covid-19/people-at-highe r-risk-from-coronavirus/whos-at-higher-risk-from-coronavirus/. Accessed 22 May 2020. 